\title{
Imaginario del conocimiento de los docentes: fragmentación y parcelación en los procesos de enseñanza en la escuela
}

Recibido: 05/10/2015

Aceptado: 15/03/2016

\section{Imaginary of teachers knowledge: Fragmentation and parcelization in teaching processes at school}

\author{
Arney Vega Martínez, avegamartinez02@gmail.com \\ David Ortega Mejía, davidortegamejia@hotmail.com \\ Universidad de Córdoba, Colombia
}

\section{Resumen}

Esta investigación tuvo como propósito comprender el imaginario del conocimiento que existe entre los docentes de grado $11^{\circ}$ de las instituciones educativas de la ciudad de Montería, expresado en la concepción y manejo que se tiene de éste y que se refleja en cada uno de los procesos pedagógicos que en su cotidianidad se promueven. Este acercamiento se realizó desde una visión compleja del conocimiento como fenómeno y proceso, con el reconocimiento de la importancia del saber como una práctica que puede ser construida desde los discursos. La metodología utilizada se referencia desde el enfoque cualitativo de tipo etnográfico, a partir de la implementación de técnicas como la observación y la entrevista. Los instrumentos aplicados para la recolección de información fueron los protocolos de observación y los protocolos de entrevista. Para el análisis se utilizaron rejillas de análisis, que permitieron categorizar los resultados de la experiencia y llevar a cabo la triangulación teórica de las categorías de análisis que surgieron en el proceso investigativo. Entre las conclusiones más relevantes, se puede afirmar que el conocimiento como fenómeno se encuentra fragmentado en su proceso y parcelado en su tratamiento, esto último se reduce al nivel de información que recurre constantemente a la memoria (repaso y entrenamiento).

Palabras claves: Imaginario, conocimiento, escuela, información, docente.

\section{Abstract}

This research aimed at understanding the imaginary of knowledge that exists between teachers in 11th grade at educational institutions in Monteria city, expressed in the conception and management that this has and is reflected on each of the pedagogical processes promoted in their daily lives. The study adopted a complex view of knowledge as phenomenan and process, recognizing the importance of knowledge as a practice that can be constructed from speech. The methodology used comes from the qualitative approach of ethnographic type and is based on the implementation of techniques such as observation and interview. The instruments used for data collection were observation protocols and the interviews. For the analysis we used analysis grids provided by María Bertely Busquets (2000), which allowed to categorize the results of the experience and to carry out the theoretical triangulation of the categories that emerged in the process. Among the most relevant conclusions, it was found that knowledge as a phenomenon is fragmented in its process and parceled out in its treatment, the latter is reduced to the level of information that constantly resorts to memory (review and training).

Keywords: Imaginary, knowledge, school, information, teacher. 


\section{Introducción}

La escuela es, fundamentalmente, un lugar donde se produce conocimiento dada su naturaleza creadora. Este proceso le da vida a una cultura escolar que encierra las diferentes formas en que se organizan socialmente las instituciones educativas, los valores, normas que imparte, concepciones de disciplina, las relaciones específicas directivo docente-estudiante que se establecen en su interior, la manera en que se concibe el conocimiento y el tratamiento que se le da al mismo en el quehacer pedagógico de la escuela.

En este sentido, la cultura escolar resulta ser el instrumento visible a través del cual la escuela lleva a cabo su trabajo en el campo del conocimiento y ejerce su labor de formadora de ciudadanos, impregnada de toda una carga valórico-ideológica que conceptualiza el rol de la educación en una sociedad específica (Magendzo, 2004). Hasta hace poco la escuela colombiana seguía en su calidad de caja negra, en la que sus procesos, discursos y prácticas se enclaustraban a sus cuatro paredes, condenadas al pacto fáustico, el cual deriva en una «escuela distributiva caracterizada por la erudición, libresca, que basa su autoridad intelectual en el manejo de teorías, conceptos y narraciones, separando la escuela de su potencialidad creativa y sentándola en el memorismo y en la necesaria autoridad del maestro» (Parra, Parra \& Lozano, 2006, p. 34), perdiendo su esencia de ser creadora de conocimiento, el cual termina siendo estéril e inaplicable en la cotidianidad.

Al respecto, resulta interesante mirar la manera como se concibe el conocimiento, el cual le dará sentido y significado al quehacer del maestro a la hora de desarrollar temáticas y conceptos en el aula. Sobre todo, si se tiene en cuenta que en la actualidad aún se mantienen prácticas tradicionalistas en cuanto al conocimiento, el cual se debe tener, poseer, adquirir sin tener las claridades y la utilidad que aquel tiene a la hora de explicar nuestro mundo fenoménico.

De ahí que la práctica pedagógica estaría orientada desde un dar y recibir que se refleja en la necesaria autoridad del maestro que tiene el conocimiento y en la pasividad y ausencia del estudiante que debe adquirirlo para más adelante y no para su presente. Todo ello con el agravante que los maestros presentan dificultades a la hora de distinguir la diferencia existente entre la información suministrada en este mundo marcado por las redes y la información, con el conocimiento, como proceso que se construye a partir de niveles e instancias que son recurrentes entre sí.

\section{Marco Teórico}

La escuela, poseedora de una cultura escolar, comprende una forma de organización social, valores y normas que la informan, un concepto y manejo del poder, de la participación, de la solución de conflictos, reglas que rigen la violencia, relaciones entre maestros y alumnos, y disciplina. También comprende la naturaleza del conocimiento y la manera de tratarlo a partir de la cual se despliegan sus procesos pedagógicos dentro y fuera del salón de clases (Parra et al. 2006).

De manera general, la cultura escolar «comprende el conjunto de saberes, concepciones prácticas y discursos que circulan en la institución educativa, [al considerarse ésta] como una organización situada en contextos específicos y como parte de la cultura que la rodea» (Parra et al. 2006, p. 27). Por ello resulta ser el instrumento visible a través del cual la escuela lleva a cabo su trabajo en el campo del conocimiento y ejerce su labor de formadora de ciudadanos, conceptualizando el rol de la educación en una sociedad específica.

Ahora bien, inclinar el interés hacia la naturaleza y el tratamiento del conocimiento en la escuela es focalizar, fundamentalmente, al maestro y su trabajo en el aula de clases desde los procesos de enseñanza que articulan, influenciados por la forma que tienen los profesores de entender el conocimiento, el aprendizaje y la enseñanza (Guerra, 2008), y unos códigos de trabajo (objetivos, 
contenido, método, medios, actividades, evaluación) en función del aprendizaje de los estudiantes (aprehensión y construcción de conocimiento).

Hablar de concepciones, creencias e ideas sobre algo es acercarnos al orden de los imaginarios, que se constituyen como un elemento decisivo que impulsa la acción (Pintos, 1995). Los imaginarios se definen como redes dotadas de significado que le dan sentido a los discursos y a las prácticas sociales, que en el caso específico del conocimiento en la cultura escolar se visibilizan en las diferentes formas en las que el docente concibe el conocimiento dentro del proceso de enseñanza y, en consecuencia, lo trabaja en el desarrollo de las clases que orienta con sus estudiantes desde su quehacer pedagógico en la escuela.

\section{Los imaginarios y su relación con el conocimiento}

El sociólogo español Juan Luis Pintos define los imaginarios como «aquellas representaciones colectivas que rigen los sistemas de identificación y de integración social, y que hacen visible la invisibilidad social» (Pintos, 1995, p. 02). Al relacionarlo con el tema del conocimiento, el análisis de éste ha pasado desapercibido, relegado socialmente, dando por cierta su veracidad, sin reflexionar sobre sus orígenes y su naturaleza, hecho que hace relevante identificar el imaginario que sobre el conocimiento existe en las escuelas. En este orden de ideas, reflexionar sobre el conocimiento se hace necesario para comprender lo que Pintos considera «la realidad social», la cual debe ser vista desde otras perspectivas, donde el unanimismo y la unidimensionalidad parecen haber quedado atrás, y por el contrario, está cargada de una alta dosis de complejidad.

Desde esta perspectiva, el mundo de las certezas ya no existe, pues la elevada complejidad de las sociedades no concibe ni centros ni límites para su comprensión, por lo que nuestra mirada se centró en observar la realidad social en las cuales se crea y recrea el conocimiento en la escuela de hoy.

\section{Humberto Maturana: El árbol del conocimiento (conocer el conocer)}

Para Humberto Maturana,

nosotros tendemos a vivir un mundo de certidumbre, de solidez perceptual indisputada, donde nuestras convicciones prueban que las cosas sólo son de la manera que las vemos, y lo que nos parece cierto no puede tener otra alternativa. Es nuestra situación cotidiana, nuestra condición cultural, nuestro modo corriente de ser humanos». (Maturana, Várela, \& Behnchke, 1984, p. 05).

Es decir, que los seres humanos consideramos que todo lo que vemos a simple vista lo damos como cierto, por el simple hecho de estar a nuestro alcance, y no lo ponemos en duda, porque así debe ser, este hecho no permite a las personas reflexionar sobre si en realidad lo que se observa es verdadero. De ahí que Maturana invite a una reflexión sobre el acto de conocer y lo que creemos conocer. De ahí que considere y defina que:

La reflexión es un proceso de conocer como conocemos, un acto de volvernos sobre nosotros mismos, la única oportunidad que tenemos de descubrir nuestras cegueras, y de reconocer que las certidumbres y los conocimientos de los otros son, respectivamente, tan abrumadoras y tan tenues como los nuestros (1984, p. 12).

El planteamiento anterior refleja una invitación a indagar la forma en que conocemos y construimos lo que a diario consideramos verdades, o verdades de los otros, lo cual 
obliga a tomar una actitud de permanente vigilia contra la tentación de la certeza, a reconocer que nuestras certidumbres no son pruebas de verdad, como si el mundo que cada uno ve fuese el mundo y no un mundo que traemos a la mano con nosotros. Nos obliga porque, al saber que sabemos, no podemos negar lo que sabemos $(1984$, p. 63).

Esto se convierte en un llamado a la actitud de estar en constante disposición a la duda, a la no certeza, a que existen verdades que no lo serán por siempre, porque precisamente son una construcción humana, que debe estar sujeta a la revisión permanente.

\section{Edgar Morín: El conocimiento del conocimiento}

El conocimiento, entendido aquí desde la perspectiva constructivista y compleja proporcionada por Morin (2006), se concibe como construcción y su noción contiene en sí diversidad y multiplicidad, por lo que no puede reducirse solo a:

Información, o percepción, o descripción, o idea, o teoría; más bien hay que concebir en él diversos modos o niveles, a los cuales correspondería cada uno de estos términos. [Así mismo], todo conocimiento contiene necesariamente: a) una competencia (aptitud para producir conocimientos), b) una actividad cognitiva (cognición) que se efectúa en función de esta competencia, c) un saber (resultante de estas actividades) (Morin, 2006, p. 20).

Para Morin, todas estas competencias y actividades cognitivas humanas están relacionadas con procesos, a la vez, energéticos, eléctricos, químicos, fisiológicos, cerebrales, existenciales, psicológicos, culturales, lingüísticos, lógicos, ideales, individuales, colectivos, personales, transpersonales e impersonales que se engranan unos en otros y que hacen del conocimiento un «fenómeno multidimensional en el sentido de que, de manera inseparable, a la vez es físico, biológico, cerebral, mental, psicológico, cultural y social». (Morin, 2006, p. 20).

Desde esta perspectiva, el conocimiento desde su construcción es netamente humano, su relación competencia-cerebro-existencia biológica-medios culturales lo humanizan, lo dinamizan y lo proyectan como un sistema abierto y cambiante, cada vez que la sociedad se transforma.

De ahí que «resulta muy diciente el hecho de que la educación, que es la que tiende a comunicar los conocimientos, permanezca ciega ante lo que es el conocimiento humano, sus disposiciones, sus imperfecciones, sus dificultades, sus tendencias tanto al error como a la ilusión y no se preocupe en absoluto por hacer conocer lo que es conocer» (Morin, 1999, p. 1).

Las implicaciones del conocimiento en la escuela se traducen en que ésta es el lugar donde se produce, además de ejercer la labor de formar ciudadanos. En este sentido, el conocimiento debe concebirse como un proceso a través del cual se efectúan operaciones cuyo conjunto constituye traducción (en signos/símbolos, y sistemas de signos/símbolos, después con los desarrollos cerebrales en representaciones, teorías, ideas); construcción (traducción constructora a partir de principios/reglas logiciales que permiten construir sistemas cognitivos que articulan información/signos/símbolos); solución de problemas, empezando por el problema cognitivo de la adecuación de la construcción traductora a la realidad que se trata de conocer, por lo que en su tratamiento no puede reflejar directamente lo real, sino más bien traducirlo y reconstruirlo en otra realidad (Morin 2006, p. 59).

\section{$4 \quad$ Rodrigo Parra Sandoval: Cultura escolaryla escuela como creadora de conocimiento} Para Parra Sandoval, la escuela es un lugar destinado, dada su naturaleza, a la producción de 
Imaginario del conocimiento de los docentes

conocimiento. Este proceso se circunscribe dentro de una cultura escolar que encierra:

las formas de organización social de la institución [educativa], los valores y normas que la informan; el concepto y manejo del poder, de la participación, de la solución de conflictos; las reglas que rigen la violencia, las relaciones entre maestros y alumnos, y la disciplina; la naturaleza del conocimiento y la manera de tratarlo (Parra et al. 2006, p. 38-39).

En este sentido, la cultura escolar «comprende el conjunto de saberes, concepciones prácticas y discursos que circulan en la institución educativa, [al considerarse ésta] como una organización situada en contextos específicos y como parte de la cultura que la rodea» (Parra et al. 2006, p. 27). En este orden, la cultura escolar resulta ser el instrumento visible a través del cual la escuela lleva a cabo su trabajo en el campo del conocimiento y ejerce su labor de formadora de ciudadanos, impregnada de toda una carga valórico-ideológica que conceptualiza el rol de la educación en una sociedad específica.

\section{Metodología}

Nuestra aproximación al tema se hizo desde un enfoque cualitativo de tipo etnográfico que permitió acercarse a la realidad de una manera simbólica y subjetiva centrando su mirada no solo en el habla, sino en lo dicho en el pensamiento, en el contenido del habla y en la intención de la misma con el propósito de comprender la realidad (Bertely, 2000). En este sentido, la investigación se basó en la implementación de técnicas como la observación y la entrevista para el estudio del caso de una institución educativa de la ciudad de Montería, en el cual se buscó comprender la naturaleza del conocimiento y su tratamiento desde los procesos de enseñanza. El estudio se enfoca en los docentes de grado once, dado el manejo disciplinar específico que desarrollan estos grados, además de la complejidad con que se maneja el conocimiento. Los instrumentos aplicados para la recolección de información fueron los protocolos de observación y los protocolos de entrevista, cuyos diseños tuvieron en cuenta la definición conceptual de Morin (2006) sobre el conocimiento como fenómeno complejo. Para el análisis de la información se utilizaron rejillas de triangulación (cotejo y teórica) aportadas por Busquets (2000), las cuales permitieron categorizar los resultados de la experiencia y llevar a cabo la triangulación teórica de las categorías de análisis que surgieron en el proceso investigativo.

\section{$1 \quad$ Fases de la investigación}

Este trabajo se desarrolló en 3 fases que, aunque tuvieron una secuencia programática, no estuvieron encasilladas en un análisis lineal durante su desarrollo. Por el contrario, se fueron retroalimento entre sí, a medida que el trabajo avanzó. En la primera fase, llamada Acercamiento al contexto, se realizó una aproximación al contexto escolar con el propósito de generar confianza y observar en la práctica (procesos de enseñanza) actitudes y formas. En la segunda fase, Ahondando en el discurso, se procuró rastrear en el discurso la manera cómo se concibe el conocimiento y desde qué postura se asume en la escuela. En esta fase se realizaron entrevistas a los docentes. La tercera fase, Producción de conocimiento se hizo todo el ejercicio de sistematización de los elementos encontrados en el desarrollo de la investigación. 


\section{Resultados \\ 1 Parcelación del conocimiento}

En el presente apartado se exponen los resultados relacionados con la manera como los docentes de una institución educativa de la ciudad de Montería conciben el conocimiento y el tratamiento que se le da desde los procesos de enseñanza. Al respecto, vale la pena recordar la mirada que tiene el conocimiento en este trabajo y sus implicaciones en el contexto escolar.

El conocimiento desde el proceso de enseñanza orientado por los docentes de una institución educativa de Montería, se encontraría como fenómeno fragmentado en su proceso y parcelado en su tratamiento en la medida en que queda reducido al nivel de información recurriendo constantemente a la memoria. Esto se hizo evidente en las entrevistas y observaciones a docentes realizadas en el marco de esta investigación, que develaron la existencia de un imaginario del conocimiento que se reduce a la transmisión de información y, en consecuencia, a la apelación de la memoria.

a Reducción del conocimiento al nivel de la información: Morin (2006) afirma que la noción de conocimiento contiene en sí diversidad y multiplicidad, por lo que no puede reducirse solo a información, o percepción, o descripción, o idea, o teoría. Más bien hay que concebir en él diversos modos o niveles, a los cuales correspondería cada uno. Esto implica entender el conocimiento como un fenómeno multidimensional y complejo que comporta unas instancias recurrentes entre sí:

Una instancia informacional (relacionada con el tratamiento de signos símbolos portadores de información con los que puede extraer informaciones de su entorno), una instancia simbólica (hace referencia al acto de computación sobre los signos/símbolos que codifican toda información y que constituyen sistemas de diferencias/similitudes que eventualmente pueden corresponder a diferencias/ variaciones/discontinuidades y a similitudes/repeticiones/continuidades que se manifiestan en el mundo exterior), una instancia memorial (se refiere a la necesidad de la computación en una capacidad de memorización o engramación de signos y la recurrencia a múltiples memorias o bancos de datos para la extracción, inscripción, duplicación, modificación o borrado), y por último una instancia logicial (se relaciona con los principios/reglas/instrucciones que gobiernan y controlan la actividad computante, es decir, la manipulación/tratamiento de los signos/símbolos que contienen información (Morin, 2006, p. 47-48).

Desde esta mirada, una de las características de los procesos de enseñanza orientados por el docente es la reducción del conocimiento al nivel de la información que se traduce en el manejo de contenidos y temas. Por ejemplo, cuando el docente recalca en una actividad evaluativa que «vamos a hacer la evaluación el tema es la agenda internacional, vamos a representar... joigan! Vamos a representar por medio de dibujos algunos temas de la agenda internacional, hagan el listado de los temas que van a representar en dibujos» (A1: 1) ${ }^{1}$, se puede observar que el docente solo se focaliza en los conceptos, mas no en los fenómenos que están relacionados con ellos y la manera cómo se relacionan con la dinámica económica, política y social de Colombia con el mundo actual. Es decir, que al no existir las relaciones entre conceptos-fenómeno-contexto, el conocimiento es tratado de forma parcelada, sin atender a su complejidad. Tal complejidad consiste en comprender las relaciones políticas y económicas que marcan la agenda internacional del país y del mundo actual, materializadas a través de acuerdos de cooperación, tratados y participación en organismos internacionales.

Lo anterior, según Parra et al. (2006), refleja un conocimiento estéril que consiste en que el individuo posee un gran cúmulo de teorías, conceptos y narraciones que pierden sentido cuando el 
individuo mismo no es capaz de relacionar y contextualizar, perdiendo a su vez la esencia creadora del conocimiento, porque éste no tiene aplicabilidad en la cotidianidad. En este sentido, una de las actividades más características en el desarrollo de las clases es, precisamente, repasar y recordar: antes de hacer la previa, vamos a repasar (A4: 9),

pero qué es lo que nos interesa a nosotros, miren, acuérdense, oigan muchachos, acuérdense que los cuatro tipos o las cuatro especies de paludismo, oigan, de las cuatro especies de paludismo, ¿cuál es la que nos interesa?, ¿la que hay en?...Montería! -Responden los estudiantes-, más que todo en el Alto Sinú y en Tierralta, Valencia, etc, (A4: 11).

Cuando nosotros estudiábamos, hacíamos, resolvíamos un cuestionario para hacer una lectura crítica sobre introducción a la filosofía, nos encontramos con un término... ¡Presocráticos! [...] el término resocrático quiere decir ¿qué? [...] antes de Sócrates...éstos señores que fueron los primeros filósofos (A3: 7).

b El entrenamiento y el repaso: píldoras para la memoria: Puesto que el conocimiento se reduce al nivel de información y excluye otros como el de percepción, descripción, idea y/o teoría, necesariamente debe recurrir a la instancia memorística (Morin, 2006). Para ello ejecuta en muchas ocasiones, durante los procesos de enseñanza, acciones de repaso y entrenamiento. Así lo deja ver el docente cuando en el desarrollo de una clase dice:

Hagamos un recorderis, bueno mañana terminamos el ciclo de las exposiciones con... les toca tuberculosis, lepra, y falta uno, lesmaniasis, -contestan los estudiantes- entonces, bueno miren hagamos un recorderis de estas enfermedades infecciosas que estamos tratando, que es el dengue (...) «vamos a recordar quien es el que aporta más al dengue»-un estudiante responde: «profe el dengue más peligroso es el dengue hemorrágico», muy bien! ¿De los dos dengues clásico y hemorrágico, cuál es el más peligroso? -Pregunta el docente, los estudiantes responden en coro «el hemorrágico», ¿qué más? -Pregunta el docente, «profe, el virus se replica en los órganos»-estudiantes, la pregunta es la siguiente [docente] ¿cómo se puede prevenir?, los estudiantes señalan «profe inyectándose, no dejando recipientes con agua, ni llantas, ni botas (A6: 18).

Pero ¿qué significa que el maestro señale a los estudiantes «repasar» antes de que ellos realicen el examen? «Repasar» hace referencia a recorrer lo que se ha estudiado para refrescar la memoria. En este sentido el docente estaría limitando el conocimiento al manejo de los conceptos-información trabajados en las diferentes clases, por ende la evaluación comprendería solo ese aspecto. Ahora, ¿a qué aspecto se refiere el docente con el término entrenamiento? Pareciera que los estudiantes solo se encargaran de memorizar de manera mecánica cierta información, la cual después irían a transmitir a las comunidades. Es decir, ¿en qué momento se hace un proceso mental que implique análisis sobre el impacto de esas enfermedades en los contextos de las comunidades intervenidas?

Estas consideraciones develan que el tratamiento dado al conocimiento se caracteriza de acuerdo a su grado de desarrollo y complejidad, desde un polo de ingenuidad o menor desarrollo relacionado con la concepción de la enseñanza por parte de los docentes como transmisión de conocimiento (Schommer, 1990; Schommer-Aikins, 2004, citado por Guerra, 2008). Ahora bien, este tipo de «píldoras» para la memoria sugieren un proceso de enseñanza «bancario». Es decir, dar-recibir-acumular información excluyendo otros procesos que hacen parte del conocimiento como la traducción/construcción/ 
solución de problemas propuesto por Morin (2006). Así lo deja ver el siguiente fragmento:

Bueno el martes empiezan ustedes, los dos, con enfermedades infecciosas...cuyo objetivo cual es muchachos es conocer, conocer, qué, las principales enfermedades infecciosas de tipo endémico sobre todo las que suceden aquí en Córdoba tenemos una que es muy prioritaria la malaria y vamos hacer, faltando diez minutos para terminarse la clase, hacemos una previa o quiz con base a los conocimientos que te estoy dando ahora en paludismo, esto es lo que hemos dado y cuyo objetivo de la clase ya lo habíamos dado, concepto de paludismo y malaria y quedamos por la patogenia... muy bien..., un recordéis de la clase pasada sobre la patogenia, quedamos por aquí (A4: 10).

En este sentido, la evaluación tendría las mismas características puesto que estarían midiendo la capacidad de retención de información, en este caso el manejo conceptual por parte del estudiante.

c Un conocimiento fragmentado: el activismo de las clases: Otro aspecto importante, además del tratamiento parcelado del conocimiento, es su fragmentación en cuanto al proceso. Edgar Morin sugiere que todo conocimiento contiene necesariamente: a) una competencia (aptitud para producir conocimientos), b) una actividad cognitiva (cognición) que se efectúa en función de esta competencia, y c) un saber (resultante de estas actividades) (Morin, 2006, p. 20).

Ahora bien, en el desarrollo de las clases constantemente nos encontramos con un conocimiento fragmentado, que abarca solo las competencias y las actividades efectuadas a partir de ellas, quedando por fuera el saber construido producto de lo anterior, esto se refleja en las siguientes situaciones:

Hemos visto todo un material que tiene que ver con la introducción a la filosofía, hoy vamos a cerrar con broche de oro con una actividad que es la número 7 (..), pero para poder leer el documento tienen que recurrir a su guía de aprendizaje donde está el cuestionario (...) a medida que ustedes van leyendo, ustedes van a ir dándole respuestas a esas preguntas, que si ustedes observan cuando ya estén respondiendo que son respuestas cortas...¿con qué fin hacemos esto? Con el fin de que ustedes aprendan a leer, lo importante es que ustedes aprendan a leer, que ustedes aprendan a interpretar, que ustedes se ubiquen, para esto son estos ejercicios de lectura, se llama lectura crítica...entonces vamos, busquen la guía, ya encontraron la actividad número 7 (A2: 4).

¿Cuál es el estándar? Comprender mediante ejemplos que la filosofía es una actividad común y necesaria que se aprende básicamente poniéndola en práctica...la filosofía no es aprenderse unos textos de memoria, la filosofía no es repetir como una máquina, la filosofía es detenerte tú a pensar, detenerte tú a argumentar, a comprender qué es lo que está pasando (A2:5).

Objetivo cual es muchachos es conocer, conocer, qué las principales enfermedades infecciosas de tipo endémico sobre todo las que suceden aquí en Córdoba tenemos una que es muy prioritaria la malaria (A4: 10).

Al respecto, las clases recaen en un activismo: entiéndase aquí como las actividades promovidas en función de una temática, en las que el docente verifica que el estudiante participe sin interesarse muchas veces por el resultado (saber construido). En el siguiente fragmento habla la docente a los estudiantes 
vas a representar como tu visualices el terrorismo, visualícenlo y represéntenlo ahííi. No les voy a calificar, ustedes pueden representar eso como ustedes lo quieran hacer, no necesariamente debe ser un dibujo de un artista de un pintor, porque ustedes no son pintores pero ustedes si tienen creatividad y ustedes si han leído sobre el problema y saben sobre el problema (A1: 2).

Las características de las actividades van a plantearse a partir de tres elementos claves que la estructuran: 1) La acción expresada en un objetivo, "¿con qué fin hacemos esto? Con el fin de que ustedes aprendan a leer (...)» (A1: 4); 2) Identificación y características del tema, «hemos visto todo un material que tiene que ver con la introducción a la filosofía, hoy vamos a cerrar con broche de oro con una actividad que es la número 7» (A1: 4); 3) Aprendizajes-resultados esperados, «que ustedes aprendan a leer, que ustedes aprendan a interpretar, que ustedes se ubiquen, para esto son estos ejercicios de lectura, se llama lectura crítica» (A1: 4). Este ejemplo, evidencia la ausencia de habilidades cognitivas que más allá del aprendizaje deben permitir al individuo establecer relaciones, diferencias, similitudes, y clasificaciones entre una cosa y otra para poder llegar realmente a la producción de un saber.

Desde Morin, las actividades cognitivas hacen parte de la actividad computante. La computación viviente es propia del ser celular y termina siendo una computación «de sí, a partir de sí, en función de sí, para sí y sobre sí», mediante operaciones de asociación (conjunción, inclusión, identificación, implicación) y de separación (diferenciación, oposición, selección, exclusión) (2006, 53-59). En este sentido, el saber se logra dentro de dos marcos y dos condiciones: unir/sintetizar (asociar, relacionar), desunir/analizar (disociar, aislar) y proyecta el aprendizaje cuando hay adquisición de información, descubrimiento de cualidades o propiedades inherentes a cosas o seres, descubrimiento de una relación entre un evento y otro, o el descubrimiento de una ausencia de unión entre dos eventos (Morin, 2006).

Teniendo en cuenta lo anterior, existe un rezago en cuanto al saber como producto de la competencia y la cognición, por lo que las habilidades cognitivas que los estudiantes deben explorar y desarrollar para producir conocimiento, llegando así a la comprensión (finalidad general de las clases), está ausente durante el proceso de construcción del conocimiento.

\section{La comprensión como finalidad del proceso de enseñanza}

Desde la visión moriana, la comprensión tiene una connotación sintética y se refiere al conocimiento que aprehende (asimila, entiende) todo aquello de lo que podemos hacernos una representación concreta, o que podemos captar de manera inmediata por analogía. En otras palabras, la comprensión constituye el modo fundamental de conocimiento para cualquier situación humana que implique subjetividad y afectividad y, más centralmente, para todos los actos, sentimientos, pensamientos de un ser percibido como individuo/sujeto (2006). Ausubel (1998) explica que cuando se logra la comprensión de un concepto o varios de ellos, estos van a permitir una explicación de los fenómenos de la realidad que percibimos, de ahí que esta habilidad logre la relación concepto-fenómeno-contexto.

Para el proceso de enseñanza desarrollado por los docentes de las escuelas monterianas, la comprensión se vuelve una máxima a la que se aspira lleguen los estudiantes al final de cada clase. A veces explícita en el objetivo,

comprender mediante ejemplos que la filosofía es una actividad común y necesaria que se aprende básicamente poniéndola en práctica...la filosofía no es aprenderse unos textos de memoria, la filosofía no es repetir como una máquina, la filosofía es detenerte tú a pensar, detenerte tú a argumentar, a comprender qué es lo que está pasando (A2: 5). 
Otras veces implícita, en la mayoría de los casos, en cada una de las actividades que se proponen en el desarrollo de la clase: «vamos a representar por medio de (...) un dibujo de cada tema, ¿cómo visualizan el terrorismo? ¿Cómo visualizan el narcotráfico? (...) Vas a representar como tu visualices el terrorismo, visualícenlo y represéntenlo ahííi» (A1: 2).

La comprensión va mucho más allá de llegar a entender, es decir, no se trata únicamente de «formarse» una idea clara de algo sino también poder «tenerla» de lo que sucede sobre el sentido y por qué de ese algo. En relación a esto, el docente utiliza diversas estrategias para la comprensión que, en muchas ocasiones, se limitan a la adquisición conceptual de lo trabajado en clases: «(...) representar (...) los temas de la agenda internacional, hagan el listado de los temas que van a representar en dibujos primero (...) Primero: derechos humanos....por medio de un dibujo, segundo: el narcotráfico, tercero: el terrorismo, cuarto: el medio ambiente» (A1: 2), «vamos a emplear en este conversatorio diez minutos, no es mucho lo que van a... procuren hablar y expresar lo que están pensando» (A2: 6), «bueno saquen la hojita para el quiz, profe hagámoslo en grupo de 2 -estudiantes-, bueno ubíquense en grupos de 2, es algo sencillo, me guardan todo, y coloquen la primera pregunta, primera pregunta» (A5: 13).

Al respecto, es posible señalar algunas estrategias a través de las cuales el docente verifica la «comprensión»:

1) La representación -bien sea mediante dibujos, sociodramas, composiciones, «ellos (los estudiantes) tienen que crear formas de expresar ese conocimiento (...) bailando, (...) en un sociodrama, con mapas conceptuales» (A7: 30).

2) El conversatorio, producto de una lectura y orientada por unas preguntas específicas: «se van ustedes a hacer la pregunta qué se logra al estudiar la filosofía y qué es la filosofía, pero no es que yo pienso igual que el otro, entre ustedes van a conversar como si estuvieran en ese pasillo (...), entonces traten de involucrarse en esa conversación» (A2: 6).

3) El quiz, que es una prueba para «medir» que tanto se adquirió el «conocimiento» aportado por el docente: «(...) y vamos hacer, faltando diez minutos para terminarse la clase, hacemos una previa o quiz con base a los conocimientos que te estoy dando ahora en paludismo» (A4: 10).

Estas estrategias obedecen a la naturaleza del conocimiento trabajado en las aulas (adquisición), las cuales se caracterizan porque el estudiante participe o realice la prueba sin que se verifique de manera efectiva la verdadera comprensión de la temática desarrollada.

\section{Influencia del docente en el aprendizaje del estudiante}

Además de la comprensión, el docente orienta sus procesos de enseñanza en función de los aprendizajes a los que pueda llegar cada uno de los estudiantes. Guskey \& Passaro (1994, citado por Guerra, 2008) conceptualiza ese deseo del docente señalando que la eficacia docente es la creencia que tienen los profesores respecto a su capacidad para influir en el logro de aprendizajes deseables en sus alumnos, incluso en aquellos considerados difíciles o poco motivados.

Ahora bien, estas creencias son importantes a la hora de establecer relaciones entre conocimiento y aprendizaje. Para Schomer 1990, citado por Guerra, (2008), mientras se cree en la complejidad del conocimiento y la gradualidad del aprendizaje existen más probabilidades de tener éxito en la comprensión y monitoreo de un texto. Por otro lado, creer en que el aprendizaje es rápido o no parece 
afectar el grado en que logra integrar el conocimiento y monitorear su comprensión.

Entre los docentes de las instituciones educativas, existe la necesidad de influir en el aprendizaje de los estudiantes y llevarlos hacia el «conocimiento» de una manera rápida y efectiva:

Tengo que hacer muchas cosas, tengo que utilizar muchas herramientas y para poder lograr que ellos, ellos se adapten al tema y ellos me digan a ver qué piensan y así yo terminar de, de llevarlos a lo que yo quiero (A7: 27), son ellos los que trabajan yo simplemente lo que hago es tratar de inducirlos por allí por lo que yo quiero, pero, pero en sí son los estudiantes ellos, ellos tienen que desenvolverse. (A7: 33).

Particularmente, entre los docentes el aprendizaje en cada clase siempre va a estar delimitado por la actividad propuesta por él para verificarlo (por lo general al final de las clases), bien sea mediante la participación a partir de una pregunta al finalizar la clase:

Yo les voy a dar la oportunidad a todos, les voy a preguntar, a todos los que están aquí presentes, se van ustedes a hacer la pregunta qué se logra al estudiar la filosofía y qué es la filosofía, pero no es que yo pienso igual que el otro, entre ustedes van a conversar como si estuvieran en ese pasillo (A2: 6).

O bien sea por un «quiz» caracterizado por la precisión de las respuestas,

bueno saquen la hojita para el quiz, profe hagámoslo en grupo de 2 (estudiantes), bueno ubíquense en grupos de 2, es algo sencillo, me guardan todo, y coloquen la primera pregunta, primera pregunta, ya, si, guarden todo, allá muchachos, ya, si, listo, (...) primera pregunta, ¿Por qué coincide, la fase caliente con la salida y destrucción de glóbulos rojos?, el profesor repite la pregunta, y dice sean precisos, segunda, ¿qué formas parasitarias, del paludismo invaden los glóbulos?, tercera pregunta, una persona que contrajo paludismo hace un año de su zona endémica, de malaria ha recaído con dicha enfermedad. ¿Si la persona no ha estado en su zona endémica por qué cree usted que tiene paludismo?, sean precisos (A4: 13).

También, la manera en que los estudiantes responden a lo que el docente plantea en las «guías de aprendizaje»: «la guía que les voy a colocar aquí, (...) la guía son 6 hojitas deben entregarme el informe de la práctica» (A5: 14).

Lo anterior refleja el querer del docente porque el estudiante aprenda de forma rápida (formación $\mathrm{y}$ adquisición de conocimiento). Esto se relaciona con la concepción del aprendizaje y conocimiento desde un grado de desarrollo menor o ingenuo, que proyecta la enseñanza como un proceso de trasmisión de conocimiento.

De esta manera, y a raíz de todos los planteamientos hechos en este apartado, se da por sentado que los procesos de enseñanza con respecto al tratamiento del conocimiento en las clases se centran en las competencias y las actividades (activismo). Existe un rezago en cuanto al saber cómo producto de las anteriores y que se constituye de unas habilidades cognitivas que los estudiantes deben explorar y desarrollar para producir conocimiento y lleguen así a la comprensión como un finalidad general de las clases. A partir de esto, el conocimiento como fenómeno se encuentra fragmentado en su proceso y parcelado en su tratamiento en el que se reduce al nivel de información. Recurre constantemente a la memoria mediante el repaso, y entrenamiento como características específicas de un conocimiento concebido desde su adquisición más que desde su construcción.

Frente a esto, vale la pena preguntarse ¿qué sentido tiene la enseñanza desde un conocimiento 
con estas características? ¿qué significado tiene el aprendizaje que subyace a la naturaleza de un conocimiento reducido y fragmentado? ¿qué sentido adquiere este modo de conocimiento en el contexto actual?

En primer lugar, la enseñanza desde un conocimiento con las características anteriormente descritas hace de este proceso un andamiaje inanimado y reducido a una concepción bancaria de dar y recibir; de mera transmisión de información que fosiliza el «conocimiento» a las cuatro paredes del aula de clases. La enseñanza de un conocimiento fragmentado y parcelado termina en la reproducción de una sociedad con las mismas características, que buscando la especificidad y especialidad se olvida de la unicidad y relaciones entre los saberes enseñados en la escuela y las realidades que la rodean.

Por otro lado, un conocimiento fragmentado, lleva a que el aprendizaje de los estudiantes esté basado únicamente en información, hecho que genera que estos no logren relacionar lo aprendido con la realidad circundante. Así las cosas, este lleva a los estudiantes a centrar su mirada solo en una parte de ella. Es decir que este hecho genera que se eduquen estudiantes limitados a ver una realidad también parcelada.

Por último, este modo de conocimiento se aleja de las dinámicas fenoménicas de la sociedad actual en que la escuela termina relegada a la reproducción de saberes. Es una escuela que realiza actividades mecánicas basadas en una competencia, lejos de fortalecer las habilidades y capacidades necesarias para comprender el todo que la rodea cada uno de esos saberes.

\section{Conclusiones y recomendaciones}

De manera general, la discusión anterior permite plantear que en la escuela los docentes no desarrollan la recurrencia ni las conexiones necesarias entre los diferentes niveles e instancias que componen y permiten la construcción de conocimiento contextualizado y conectado con las realidades que implican al individuo. Esto genera que se suministre a los estudiantes, en la mayoría de los casos, solamente información que corresponde a una de las instancias que involucra el conocimiento como proceso y fenómeno multidimensional. La condición anterior refleja un proceso de enseñanza-aprendizaje que orienta la transferencia y adquisición de un conocimiento fragmentado, y que sugiere la formación de un individuo incapaz de comprender y encontrarle sentido a su realidad.

Asistimos así ante un imaginario del conocimiento caracterizado por la correspondencia entre la fragmentación de su proceso que se reduce a la enunciación de las competencias, la mecanización de contenidos, y la parcelación en su tratamiento que significa la socialización unidireccional de los contenidos concebidos como conocimiento. ¿Por qué hablar de correspondencia en la totalización expresada en el imaginario del conocimiento de los docentes?

De manera general, hablar de «correspondencia» es hacer referencia a la relación de complementación, concordancia, equivalencia o simetría que existe o se establece entre dos o más cosas. En este sentido, la fragmentación y la parcelación del conocimiento re-creado en el imaginario de los docentes encuentra en el enfoque reduccionista/pensamiento simplificador (Morin, 1990) su adecuada correspondencia, pues expone el proceso y tratamiento de un conocimiento unidimensional, abstracto e inaplicable frente a las conmociones que generan las realidades de una vida planetaria en mutación (Nicolescu, 1996).

Es ahí donde radica el verdadero problema, puesto que el desarrollo de un pensamiento con estas características, a la hora de atender la complejidad del mundo fenoménico que nos rodea, promueve una

inteligencia que no sabe hacer otra cosa que separar, rompe lo complejo del mundo en fragmentos disociados, fracciona los problemas, convierte lo multidimensional en unidimensional. Atrofia las 
posibilidades de comprensión y de reflexión, eliminando también las posibilidades de un juicio correctivo o de una visión a largo plazo. Su insuficiencia para tratar nuestros problemas más graves constituye uno de los problemas más graves que enfrentamos (Morin, 1999, p. 14).

Veamos a continuación un esquema de la cuestión anterior:

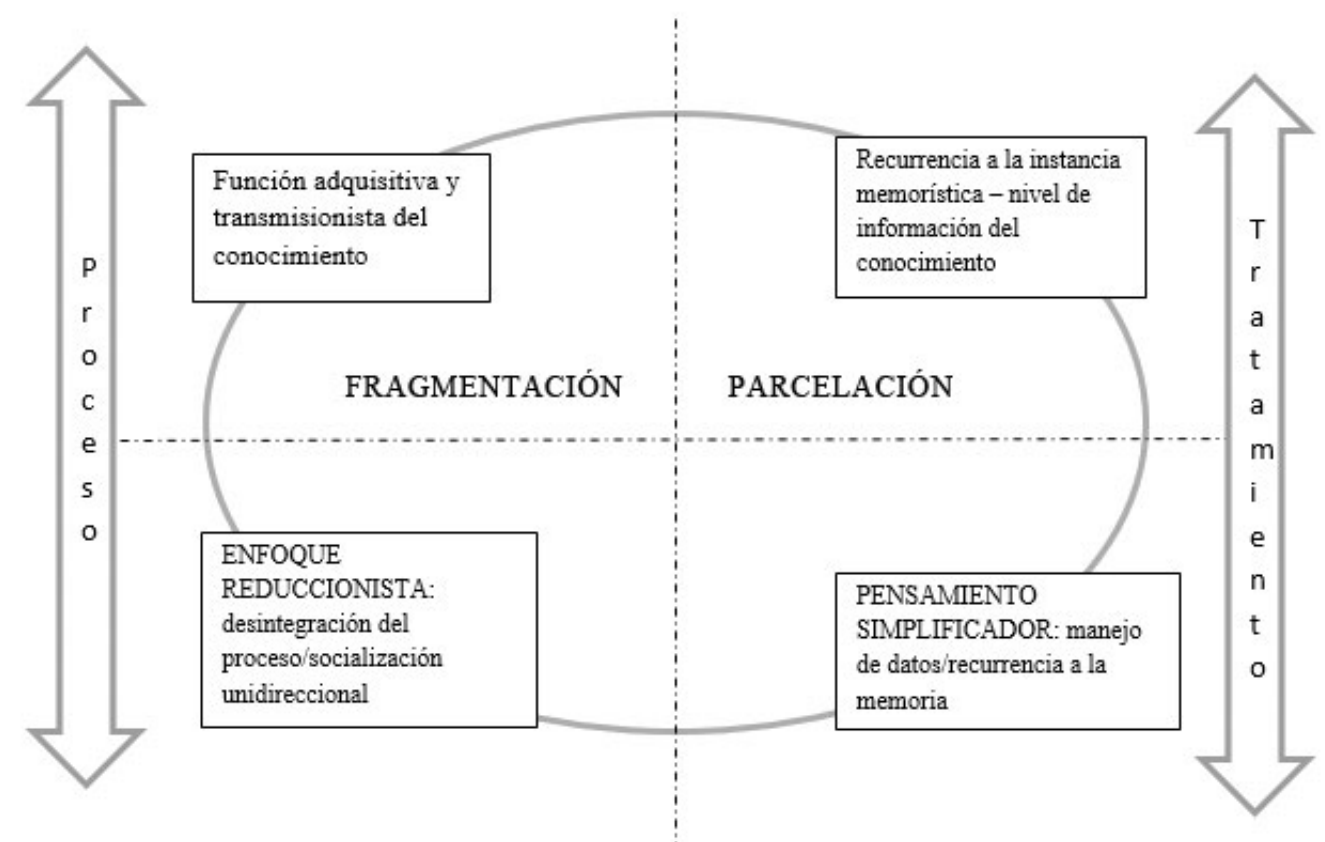

Figura 1. Imaginario del conocimiento de los docentes

El primer cuadrante (superior-izquierda) nos va a definir la función adquisitiva/transmisionista del conocimiento. Este se basa en el manejo de datos y la reducción de fenómenos complejos que implica procesos más allá de los definidos por la instancia memorística. Desde esta perspectiva los procesos de enseñanza se enfrascan en un «dar-recibir» que lo fragmentan. Aquí solo importa la transferencia de contenidos concebidos como «conocimiento» totalmente descontextualizados/desconectados, en muchas ocasiones, de las realidades mediatas e inmediatas del estudiante. Esto se relaciona con el segundo cuadrante ubicado en la parte inferior-izquierda. El conocimiento fragmentado en su proceso desarticula la complejidad del mismo desde un enfoque reduccionista que comprime el conocer a la enunciación de la competencia y a la mecanización de contenido que se socializa de manera unidimensional.

Un enfoque reduccionista consiste en «remitirse a una sola serie de factores para solucionar la totalidad de los problemas planteados por la crisis multiforme que atravesamos actualmente». (Peccei y Ikeda1986, citado por Morin, 1999, p. 14), lo cual sugiere la necesidad de fraccionar los problemas sin tener en cuenta el todo que los conforman. Frente a esto, se sostiene que «cuanto más multidimensionales se vuelven los problemas, se es más incapaz de pensar su multidimensionalidad. Cuanto más progresa la crisis, más progresa la incapacidad para pensar la crisis; cuanto más globales se vuelven los problemas, menos se piensa en ellos» (Morin, 1999, p. 15). En la medida en que un conocimiento «insular» es incapaz de encarar el contexto y el complejo global con todas sus particularidades.

El primer y segundo cuadrantes ubicados a la derecha, definen la parcelación del conocimiento 
desde su tratamiento, sugiriendo la reducción de este al nivel de información y la recurrencia constante a la memoria, definida por dos acciones: repasar y entrenar. Esta condición sienta sus bases -y a la vez lo promueve, en el pensamiento simplificador.

Por otro lado, una de las características de los procesos de enseñanza con respecto al tratamiento del conocimiento en las clases es que se centran en las competencias y las actividades (activismo). Existe un rezago en cuanto al saber como producto de las anteriores y que se constituye de unas habilidades cognitivas que los estudiantes deben explorar y desarrollar para producir conocimiento y lleguen así a la comprensión (finalidad general de las clases). Además, el conocimiento como fenómeno se encuentra fragmentado en su proceso y parcelado en su tratamiento. Esto último se reduce al nivel de información que recurre constantemente a la memoria (repaso y entrenamiento).

Cabe señalar que a pesar de estar inmersos en la «sociedad del conocimiento» y tener fácil acceso a la información, con la cual actualizar constantemente el quehacer pedagógico en el aula, las prácticas de los docentes aún se encuentran ancladas al tradicionalismo pedagógico característico de una escuela de naturaleza verbal que privilegia la erudición y esteriliza el conocimiento. Lo anterior abre la discusión sobre la importancia de formar en habilidades más que en contenidos y que éstos sean tomados como un medio y como un fin. Los docentes reconocen poco la autonomía que poseen a la hora de orientar los procesos en la escuela. Por el contrario, al parecer ven los lineamientos del MEN como la norma o camisa de fuerza que guía tales procesos, quitándole la naturaleza creadora a la escuela y relegándola a la mera transmisión de información considerada por los maestros como «conocimiento».

Por último, el maestro está llamado a autoreconocerse en un rol dentro del proceso de enseñanzaaprendizaje que le permita la apertura de espacios a los estudiantes para desarrollar habilidades cognitivas.

\section{Notas}

${ }^{1}$ Esta convención corresponde al ordenamiento de los registros de los datos (observaciones y entrevistas) desde lo planteado por Aracely de Tezanos (2004), implicó «tanto un aspecto práctico de manejo de los mismos, como un proceso de verificación de las coherencias entre los contenidos que abre camino a la escritura del texto descriptivo [en primer lugar. La autora a este proceso lo llama la triangulación de cotejo], para diferenciarla de la triangulación interpretativa, que está en el inicio y producción del proceso interpretativo» (p. 151). En este sentido, A1:1 corresponde al anexo 1 página 1 de los registros de observaciones.

\section{Referencias}

Bertely Busquets, M. (2000). Conociendo nuestras escuelas. Un acercamiento etnográfico a la cultura escolar. Colección Maestros y enseñanzas. México DF: Paidós.

Bobadilla Goldschmidt, M., Cárdenas Pérez, A. V., Dobbs Díaz, E., \& Soto Bustamante, A. M. (2009). "Los rodeos de la práctica": representaciones sobre el saber docente en el discurso de estudiantes de pedagogía. Estudios pedagógicos (Valdivia), 35(1), 239-252.

De Tezanos, A. (2004). Una etnografía de la etnografía. Bogotá D.C.: Ediciones Antropos Ltda., colección pedagogía siglo XXI.

Guerra, P. (2008). Creencias epistemológicas y de eficacia docente de profesores que postulan al programa de acreditación de excelencia pedagógica y su relación con las prácticas de aula (tesis de maestría). Pontificia Universidad Católica de Chile, Santiago, Chile.

Guber, R. (2001). La etnografía: método, campo y reflexividad (Vol. 11). Editorial Norma. Recuperado 
de http://correo3.perio.unlp.edu.ar/catedras/system/files/guber_r._-_la_etnografia_cap_4_0.pdf Maturana, H. R., \& Varela, F. J. (1990). El árbol del conocimiento: las bases biológicas del conocimiento humano. Madrid: Debate.

Morin, E. (1999). Los siete saberes necesarios para la educación del futuro. Recuperado de http:// dide.minedu.gob.pe/xmlui/bitstream/handle/123456789/1448/Los\%207\%20saberes\%20 necesarios $\% 20$ para $\% 201 \mathrm{a} \% 20$ educaci\%C3\%B3n\%20del\%20futuro.pdf?sequence $=1$

Morin, E. (1988). El Método III. El conocimiento del conocimiento. Madrid: Cátedra, 2, 24.

Morin, E. (2002). Sociología. Madrid: Editorial Tecnos (Grupo Anaya, S.A.).

Nava, P, José María s.f. (2011) El consumo de la internet e imaginarios alrededor del conocimiento en adolescencias. Recuperado de: http://www.comie.org.mx/congreso/memoriaelectronica/v10/ pdf/area_tematica_07/ponencias/1211-F.pdf

Osorio, C. A. M., \& Álvarez, N. M. Caracterización del discurso Pedagógico en el aula de clase de la Universidad del Quíndío. Recuperado de http://www.uniquindio.edu.co/uniquindio/ revistainvestigaciones/adjuntos/pdf/

Parra Sandoval, R., Parra Sandoval, F., \& Lozano, M. (2006). Tres talleres: Hacia una pedagogía de la investigación etnográfica en la escuela. Bogotá DC Edición del Convenio Andrés Bello, Unidad Editorial.

Peña, N. M. (2013). La escuela como imaginario social. Apuntes para una escuela dinámica. Magistro, 6(12), 53-70. Recuperado de http://revistas.usantotomas.edu.co/index.php/magistro/article/ viewFile/626/912

Pimienta P, Julio (2012). Estrategias de enseñanza-aprendizaje. Docencia universitaria basada en competencias. México: Pearson Educación, S.A. de C.V., ISBN: 978-607-37-0752-2.

Pintos, J. L. (1995). Los imaginarios sociales: la nueva construcción de la realidad social. Editorial SAL TERRAE.

Sánchez Capdequí, C. (1999). Imaginación y sociedad: una hermenéutica creativa de la cultura. Madrid: Tecnos-Universidad Pública de Navarra. 